\title{
A Large French Case-Control Study Emphasizes the Role of Rare Mc1R Variants in Melanoma Risk
}

\author{
Hui-Han Hu, ${ }^{1,2}$ Mériem Benfodda, ${ }^{2}$ Nicolas Dumaz, ${ }^{1}$ Steven Gazal, ${ }^{3}$ \\ Vincent Descamps, ${ }^{1,4}$ Agnès Bourillon, ${ }^{2}$ Nicole Basset-Seguin,, ${ }^{1,5}$ Angélique Riffault, ${ }^{2}$ \\ Khaled Ezzedine, ${ }^{6,7}$ Martine Bagot, ${ }^{1,5}$ Armand Bensussan, ${ }^{1,5}$ Philippe Saiag, ${ }^{8,9}$ \\ Bernard Grandchamp, ${ }^{2}$ and Nadem Soufir ${ }^{1,2}$ \\ ${ }^{1}$ INSERM U976, Centre de Recherche sur la Peau, Hôpital Saint Louis, 1 Avenue Claude Vellefaux, 75010 Paris, France \\ ${ }^{2}$ Laboratoire de Génétique, Hôpital Bichat Claude Bernard, APHP, IFR02, Université Paris 7 , \\ 46 rue Henri Hucahrd, 75018 Paris, France \\ ${ }^{3}$ UMR S738, Faculté de Médecine Xavier Bichat, 16 rue Henri Huchard, 75018 Paris, France \\ ${ }^{4}$ Service de Dermatologie, Hôpital Bichat Claude Bernard, APHP, Université Paris 7, 46 rue Henri Hucahrd, 75018 Paris, France \\ ${ }^{5}$ Service de Dermatologie, Hôpital Saint Louis, APHP, Université Paris 7, 1 Avenue Claude Vellefaux, 75010 Paris, France \\ ${ }^{6}$ Service de Dermatologie, CHU Bordeaux, Université V Segalen Bordeaux 2, 12 rue Dubernat 33404 Bordeaux, France \\ ${ }^{7}$ INSERM U876, 146 rue Leo Saignat, 33076 Bordeaux, France \\ ${ }^{8}$ Service de Dermatologie, Hôpital Ambroise Paré, APHP, 9 Avenue Charles-de-Gaulle, 92100 Boulogne Billancourt, France \\ ${ }^{9}$ Université Saint Quentin en Yvelines, 55 Avenue de Paris, 78000 Versailles, France
}

Correspondence should be addressed to Hui-Han Hu; andrea.hul712@gmail.com

Received 14 February 2014; Accepted 12 March 2014; Published 10 April 2014

Academic Editor: Jean-Pierre Molès

Copyright (C) 2014 Hui-Han Hu et al. This is an open access article distributed under the Creative Commons Attribution License, which permits unrestricted use, distribution, and reproduction in any medium, provided the original work is properly cited.

Background. The MC1R gene implicated in melanogenesis and skin pigmentation is highly polymorphic. Several alleles are associated with red hair and fair skin phenotypes and contribute to melanoma risk. Objective. This work aims to assess the effect of different classes of $M C 1 R$ variants, notably rare variants, on melanoma risk. Methods. MC1R coding region was sequenced in 1131 melanoma patients and 869 healthy controls. MC1R variants were classified as RHC $(R)$ and non-RHC $(r)$. Rare variants (frequency $<1 \%)$ were subdivided into two subgroups, predicted to be damaging $(D)$ or not $(n D)$. Results. Both $R$ and $r$ alleles were associated with melanoma $(\mathrm{OR}=2.66[2.20-3.23]$ and $1.51[1.32-1.73])$ and had similar population attributable risks $(15.8 \%$ and $16.6 \%)$. We also identified 69 rare variants, of which 25 were novel. $D$ variants were strongly associated with melanoma $(\mathrm{OR}=2.38[1.38-4.15])$ and clustered in the same MC1R domains as $R$ alleles (intracellular 2, transmembrane 2 and 7). Conclusion. This work confirms the role of $R$ and $r$ alleles in melanoma risk in the French population and proposes a novel class of rare $D$ variants as important melanoma risk factors. These findings may improve the definition of high-risk subjects that could be targeted for melanoma prevention and screening.

\section{Introduction}

The incidence of cutaneous melanoma, the most lethal type of skin cancer, is increasing in western countries, doubling every ten years [1]. Melanoma is a complex disease that arises through multiple etiological pathways [2]. Ultraviolet radiation exposure is the main environmental cause, and pigmentation characteristics such as light skin, hair and eye colour, and high number of nevi have also been identified as melanoma risk factors [3].

Germline mutations in high-penetrance melanoma predisposing genes CDKN2A and CDK4 have been found in $20 \%$ of familial melanoma cases [4]. Recently, a third major gene, BAP1, that predisposes to melanoma (mainly ocular), mesothelioma, and possibly additional cancers has been identified [5-7]. In addition, numerous low penetrant 
susceptibility variants, which modulate melanoma risk, have also been described. These genes are mainly involved in melanogenesis (MC1R, ASIP, TYR, TYRP1, and SLC45A2) and melanocyte differentiation (MITF, KIT, and EDNRB) [812]. Recently, variants in other pathways, such as DNA repair, genome maintenance integrity, and immunological pathways (TERT-CLPTM1, CASP8, ATM, and MX2), have also been linked to melanoma predisposition [13-17].

Among pigmentation genes, $M C 1 R$, which is the most studied, is associated with human skin pigmentation and melanoma susceptibility. MC1R, the receptor for $\alpha$-melanocyte stimulating hormone $(\alpha-\mathrm{MSH})$, is a G protein coupled receptor with seven transmembrane domains that regulates the relative concentration of brown-black eumelanin and red-yellow pheomelanin [18]. Eumelanin has been shown to reduce the accumulation of DNA photodamage and to protect melanocytes from UV-induced apoptosis. Pheomelanin is, on the contrary phototoxic, generating oxidative stress by the production of reactive oxygen species [19-21].

$M C 1 R$ is highly polymorphic within Caucasian populations [21]. A recent review has documented 57 nonsynonymous and 25 synonymous polymorphisms in different populations [22]. RHC (red hair color) variants (also called " $R$ " alleles) lead to nonfunctional or diminished functional receptors [23], preferentially induce pheomelanin production, and are therefore associated with red hair, light skin, poor tanning ability, and heavy freckling [24-27]. Other $M C 1 R$ variants that impact less strongly on MC1R function are called non-RHC variants and are labelled " $r$ " alleles.

Numerous association studies have demonstrated the important role of $M C 1 R R$ variants in melanoma predisposition $[8,11,28,29]$. The influence of $M C 1 R r$ variants on melanoma risk has also been reported but there are several discrepancies in the different published works [4, 29-31]. In addition, to date there is no conclusion on the role of rare $M C 1 R$ variants in melanoma. In this large French case-control study, we investigated the role of different classes of MC1R variants in melanoma risk, focussing particularly on the role of rare $M C 1 R$ variants.

\section{Patients and Methods}

2.1. Studied Populations. A cohort of 1131 Caucasian melanoma patients was recruited between 2002 and 2008 from the dermatology departments of all university-affiliated hospitals in Paris (the MelanCohort). The main characteristics of the patients have been previously described [32]. Melanoma was sporadic in 784 patients (69\%), including 81 patients (7\%) who had multiple melanomas and 229 patients $(20 \%)$ who had familial melanoma (at least 2 cases in first- or second-degree relatives, including the proband). Among the familial and multiple sporadic cases, $8.5 \%$ of patients carried mutations in the CDKN2A or CDK4 gene.

The control group comprised 869 ethnically matched skin cancer-free blood donors recruited from the EFS (Etablissement Français du Sang) in Bichat and Saint-Louis hospitals over the same period. These subjects have previously been described and used as controls in case-control studies [3234].
Data from patients and controls regarding sex, age, ethnic origin, date of birth, anatomoclinical data, pigmentation characteristics (hair, eye, and skin colours), skin type (Fitzpatrick classification I to IV), nevus count $(<10,10-50,51-$ 100 , and $>100$ ), and heavy freckles (yes/no) were collected in a standard document. Ancestry was investigated through birth location of parents and grandparents, and only those with a Caucasian ancestry were retained for the study. The pigmentation characteristics of patients and controls are summarized in Supplementary Table 1 (see Supplementary Materials available online at http://dx.doi.org/10.1155/2014/925716). All subjects signed an informed consent form and provided a blood sample.

2.2. Sequencing and Mutational Analysis. The coding sequence of MC1R deposited in GenBank (NM_002386.3) was amplified with 2 couples of primer selected by UCSC Genome Browser Gateway (data available upon request) in 1131 melanoma patients and 869 controls. The PCR mix contained $20 \mathrm{ng}$ of genomic DNA, $2.5 \mathrm{mM} \mathrm{MgCl}, 50 \mu \mathrm{M}$ of each dNTP, $400 \mathrm{nM}$ of each primer, and $0.5 \mathrm{U}$ Ampli TaqGold polymerase (Applied Biosystems, Courtaboeuf, France). A $62^{\circ} \mathrm{C}$ annealing temperature was used for PCR amplification. PCR products were verified on a $2 \%$ agarose gel and purified by EXOSAP-IT (USB Corporation, OH, USA). Sequencing reaction was performed on 8900 Fast Thermal Cycler (Applied Biosystems), using 10 ng of purified PCR products and the Big-Dye Terminator Cycle Kit (Applied Biosystems). Sequence analysis was performed with an ABI-Prism 3130 automated sequencer (Applied Biosystems) and read with SeqScape software v2.5 (Applied Biosystems).

2.3. Classification of MC1R Variants. The functional impact of numerous $M C 1 R$ variants has been assessed in previous studies [47] (Supplementary Table 2). Some variants lead to poor MC1R expression, due to endoplasmic reticulum (ER) retention or aberrant trafficking from ER to Golgi [50]. Other variants result in a diminished functional receptor due to lower affinity for $\alpha$-MSH, reduced coupling with cAMP, or decreased ability to stimulate cAMP production [47, 50-53].

In order to predict the impact on protein function of $M C 1 R$ variants, we used in silico prediction tools, SIFT (http://sift.jcvi.org/), SNPs3D (http://www.snps3d.org/), and PolyPhen (http://genetics.bwh.harvard.edu/pph/). Rare variants, which were defined by an allele frequency $<1 \%$ and predicted to be damaging by at least 1 of 3 prediction tools, were predicted to be damaging $(D)$ variants, while variants without any damaging effect were regarded as nondamaging $(n D)$ variants. Variants that had a clear functional impact (i.e., nonsense or frameshift mutations) were classified as damaging $(D)$ variants.

2.4. Statistical Analysis. Statistical analysis was performed by using PASW software version 18. The level of significance for all tests corresponded to an alpha error rate of $5 \%$. All odds ratios (OR) were calculated with $95 \%$ confidence intervals. 
TABLE 1: All variants found in the study.

\begin{tabular}{|c|c|c|c|c|c|c|c|}
\hline \multirow{2}{*}{ Nucleotide change } & \multirow[b]{2}{*}{$\begin{array}{l}\text { Amino acid } \\
\text { change }\end{array}$} & \multicolumn{2}{|c|}{ Number of chromosome } & \multirow{2}{*}{$\begin{array}{l}\text { Predicted to be } \\
\text { damaging }(D) \\
\text { variant }^{\mathrm{a}}\end{array}$} & \multirow{2}{*}{$\begin{array}{c}\text { Rare } \\
\text { variant }^{\mathrm{b}}\end{array}$} & \multirow[b]{2}{*}{$\begin{array}{c}\text { Novel } \\
\text { variant }^{\mathrm{c}}\end{array}$} & \multirow[b]{2}{*}{ Reference } \\
\hline & & $\begin{array}{c}\text { Patients } \\
(\mathrm{chr}=2262)\end{array}$ & $\begin{array}{c}\text { Controls } \\
(\mathrm{chr}=1738)\end{array}$ & & & & \\
\hline \multicolumn{8}{|l|}{ Nonsynonymous } \\
\hline c. $100 \mathrm{C}>\mathrm{T}$ & p.R34W & & 1 & No & Yes & Yes & \\
\hline c. $104 \mathrm{G}>\mathrm{A}$ & p.C35Y & 1 & & Yes & Yes & No & [35] \\
\hline c. $112 \mathrm{G}>\mathrm{A}$ & p.V38M & 2 & 3 & No & Yes & No & [35] \\
\hline c. $122 \mathrm{C}>\mathrm{G}$ & p.S41C & & 2 & Yes & Yes & Yes & \\
\hline c.133T > C (rs61996344) & p.F45L & 2 & & Yes & Yes & No & [36] \\
\hline c.178G $>$ T (rs1805005) & p.V60L & 359 & 254 & Yes & No & No & {$[25]$} \\
\hline c. $199 \mathrm{C}>\mathrm{T}$ & p.R67W & & 2 & Yes & Yes & No & {$[37]$} \\
\hline c. $200 \mathrm{G}>\mathrm{A}(\mathrm{rs} 34090186)$ & p.R67Q & 1 & 1 & No & Yes & No & {$[38]$} \\
\hline c. $205 \mathrm{C}>\mathrm{G}$ & p.L69V & & 1 & Yes & Yes & Yes & \\
\hline c. $241 \mathrm{G}>\mathrm{C}$ & p.A81P & 1 & & Yes & Yes & No & {$[24]$} \\
\hline c. $247 \mathrm{~T}>\mathrm{C}(\mathrm{rs} 34474212)$ & p.S83P & 5 & 1 & Yes & Yes & No & [39] \\
\hline c. $252 \mathrm{C}>\mathrm{A}(\mathrm{rs} 1805006)$ & p.D84E & 23 & 13 & RHC & No & No & [27] \\
\hline c. $274 \mathrm{G}>\mathrm{A}$ & p.V92M & 188 & 113 & Yes & No & No & [27] \\
\hline c. $284 \mathrm{C}>\mathrm{T}(\mathrm{rs} 34158934)$ & p.T95M & 6 & 2 & Yes & Yes & No & {$[27]$} \\
\hline c. $296 \mathrm{~T}>\mathrm{C}$ & p.L99P & 1 & & Yes & Yes & Yes & \\
\hline c.310G > A (rs2229617) & p.G104S & & 1 & Yes & Yes & No & {$[24]$} \\
\hline c. $350 \mathrm{~A}>\mathrm{T}$ & p.D117V & 1 & & Yes & Yes & Yes & \\
\hline c.359T > C (rs33932559) & p.I120T & 1 & & Yes & Yes & No & {$[35]$} \\
\hline c. $364 \mathrm{G}>\mathrm{A}$ & p.V122M & 1 & 4 & No & Yes & No & {$[40]$} \\
\hline c. $373 \mathrm{~T}>\mathrm{C}$ & p.C125R & 1 & & Yes & Yes & No & {$[41]$} \\
\hline c. $389 \mathrm{C}>\mathrm{T}$ & p.S130F & 1 & & Yes & Yes & Yes & \\
\hline c. $415 \mathrm{G}>\mathrm{A}$ & p.A139T & 1 & & Yes & Yes & No & {$[31]$} \\
\hline c. $417 \mathrm{G}>\mathrm{A}$ & p.V140M & 1 & & No & Yes & Yes & \\
\hline c. $419 \mathrm{~T}>\mathrm{G}$ & p.V140G & & 1 & Yes & Yes & Yes & \\
\hline c. $424 \mathrm{C}>\mathrm{T}$ & p.R142C & 1 & & Yes & Yes & No & {$[42]$} \\
\hline c. $425 \mathrm{G}>\mathrm{A}(\mathrm{rs} 11547464)$ & p.R142H & 29 & 13 & RHC & No & No & {$[25]$} \\
\hline c. $451 \mathrm{C}>\mathrm{T}(\mathrm{rs} 1805007)$ & p.R151C & 211 & 76 & RHC & No & No & {$[25]$} \\
\hline c. $456 \mathrm{C}>\mathrm{A}$ & p.Y152X & 1 & & Yes & Yes & No & {$[43]$} \\
\hline c. $464 \mathrm{~T}>\mathrm{C}(\mathrm{rs} 1110400)$ & p.I155T & 35 & 14 & Yes & No & No & {$[25]$} \\
\hline c. $467 \mathrm{~T}>\mathrm{C}$ & p.V156A & & 1 & Yes & Yes & No & {$[31]$} \\
\hline c. $478 \mathrm{C}>\mathrm{T}(\mathrm{rs} 1805008)$ & p.R160W & 152 & 59 & RHC & No & No & {$[25]$} \\
\hline c. $479 \mathrm{G}>\mathrm{A}$ & p.R160Q & 2 & & Yes & Yes & No & {$[36]$} \\
\hline c.488G $>$ A (rs885479) & p.R163Q & 75 & 57 & Yes & No & No & {$[25]$} \\
\hline c. $512 \mathrm{C}>\mathrm{A}$ & p.A171D & & 1 & Yes & Yes & No & {$[43]$} \\
\hline c. $613 \mathrm{G}>\mathrm{C}$ & p.V205L & 1 & & Yes & Yes & Yes & \\
\hline c.637C > T (rs144239448) & p.R213W & 3 & 4 & Yes & Yes & No & {$[36]$} \\
\hline c. $652 \mathrm{G}>\mathrm{A}$ & p.A218T & & 1 & Yes & Yes & No & {$[29]$} \\
\hline c. $664 \mathrm{G}>\mathrm{T}$ & p.A222S & 1 & & No & Yes & Yes & \\
\hline c. $667 \mathrm{C}>\mathrm{T}$ & p.R223W & 1 & & Yes & Yes & Yes & \\
\hline c. $707 \mathrm{G}<\mathrm{A}$ & p.G236D & 1 & & Yes & Yes & Yes & \\
\hline c. $766 \mathrm{C}>\mathrm{T}$ & p.P256S & 1 & 1 & Yes & Yes & No & {$[43]$} \\
\hline c. $801 \mathrm{C}>\mathrm{A}$ & p.C267X & 1 & & Yes & Yes & Yes & \\
\hline c. $820 \mathrm{G}>\mathrm{A}$ & p.G274S & 1 & & No & Yes & No & {$[44]$} \\
\hline
\end{tabular}


TABLE 1: Continued.

\begin{tabular}{|c|c|c|c|c|c|c|c|}
\hline \multirow[b]{2}{*}{ Nucleotide change } & \multirow[b]{2}{*}{$\begin{array}{l}\text { Amino acid } \\
\text { change }\end{array}$} & \multicolumn{2}{|c|}{ Number of chromosome } & \multirow{2}{*}{$\begin{array}{l}\text { Predicted to be } \\
\text { damaging }(D) \\
\text { variant }^{\mathrm{a}}\end{array}$} & \multirow{2}{*}{$\begin{array}{c}\text { Rare } \\
\text { variant }^{\mathrm{b}}\end{array}$} & \multirow{2}{*}{$\begin{array}{c}\text { Novel } \\
\text { variant }^{\mathrm{c}}\end{array}$} & \multirow[b]{2}{*}{ Reference } \\
\hline & & $\begin{array}{c}\text { Patients } \\
(\mathrm{chr}=2262)\end{array}$ & $\begin{array}{c}\text { Controls } \\
(\mathrm{chr}=1738)\end{array}$ & & & & \\
\hline c. $832 \mathrm{~A}>\mathrm{G}$ & p.K278E & 3 & 1 & Yes & Yes & No & {$[24]$} \\
\hline c. $842 \mathrm{~A}>\mathrm{G}(\mathrm{rs} 141177570)$ & p.N281S & & 1 & Yes & Yes & No & {$[45]$} \\
\hline c. $853 \mathrm{G}>\mathrm{A}$ & p.A285T & 1 & & No & Yes & Yes & \\
\hline c. $854 \mathrm{C}>\mathrm{G}$ & p.A285G & 1 & & Yes & Yes & Yes & \\
\hline c. $861 \mathrm{C}>\mathrm{G}$ & p.I287M & 2 & & Yes & Yes & No & {$[46]$} \\
\hline c. $865 \mathrm{~T}>\mathrm{C}$ & p.C289R & & 1 & Yes & Yes & No & [47] \\
\hline c. $880 \mathrm{G}>\mathrm{C}(\mathrm{rs} 1805009)$ & p.D294H & 85 & 35 & RHC & No & No & {$[27]$} \\
\hline c. $892 \mathrm{~T}>\mathrm{C}$ & p.Y298H & 1 & & Yes & Yes & No & {$[42]$} \\
\hline c. $895 \mathrm{G}>\mathrm{A}$ & p.A299T & 1 & & Yes & Yes & No & [25] \\
\hline c. $917 \mathrm{G}>\mathrm{A}$ & p.R306H & 1 & & Yes & Yes & No & {$[45]$} \\
\hline c. $928 \mathrm{~A}>\mathrm{C}$ & p.K310Q & 1 & & No & Yes & Yes & \\
\hline c. $951 \mathrm{G}>\mathrm{T}$ & p.W317C & & 1 & Yes & Yes & Yes & \\
\hline \multicolumn{8}{|l|}{ Insertion/deletion } \\
\hline c.86_87 insA & & 4 & & Yes & Yes & No & {$[46]$} \\
\hline c. $481 \_482$ insG & & 1 & & Yes & Yes & Yes & \\
\hline c.524_525 ins T & & 1 & & Yes & Yes & Yes & \\
\hline \multicolumn{8}{|l|}{ Synonymous } \\
\hline c. $366 \mathrm{G}>\mathrm{A}$ & p.V122V & 1 & & No & Yes & No & {$[29]$} \\
\hline c. $414 \mathrm{C}>\mathrm{T}$ & p.I138I & & 1 & No & Yes & No & {$[38]$} \\
\hline c. $426 \mathrm{C}>\mathrm{A}$ & p.R142R & & 2 & No & Yes & Yes & \\
\hline c. $471 \mathrm{C}>\mathrm{T}$ & p.T157T & & 1 & No & Yes & Yes & \\
\hline c. $477 \mathrm{G}>\mathrm{C}$ & p.P159P & & 1 & No & Yes & Yes & \\
\hline c. $478 \mathrm{C}>\mathrm{A}$ & p.R160R & 1 & & No & Yes & No & {$[48]$} \\
\hline c. $483 \mathrm{G}>\mathrm{A}$ & p.A161A & & 1 & No & Yes & No & [29] \\
\hline c. $504 \mathrm{C}>\mathrm{T}(\mathrm{rs} 34612847)$ & p.I168I & & 1 & No & Yes & No & {$[38]$} \\
\hline c.531G > A $(\mathrm{rs} 145781072)$ & p.T177T & 1 & 1 & No & Yes & No & \\
\hline c. $537 \mathrm{C}>\mathrm{T}$ & p.F179F & & 1 & No & Yes & Yes & \\
\hline c. $621 \mathrm{C}>\mathrm{T}$ & p.Y207Y & & 1 & No & Yes & No & {$[31]$} \\
\hline c. $690 \mathrm{G}>\mathrm{C}$ & p.P230P & & 3 & No & Yes & No & {$[24]$} \\
\hline c.699G > A (rs146544450) & p.Q233Q & 6 & 10 & No & Yes & No & {$[46]$} \\
\hline c. $792 \mathrm{C}>\mathrm{T}$ & p.I264I & & 4 & No & Yes & No & [49] \\
\hline c. $828 \mathrm{C}>\mathrm{T}$ & p.I276I & & 1 & No & Yes & No & {$[31]$} \\
\hline c. $873 \mathrm{C}>\mathrm{T}$ & p.A291A & 1 & & No & Yes & Yes & \\
\hline c. $894 \mathrm{C}>\mathrm{T}(\mathrm{rs} 143395134)$ & p.Y298Y & & 2 & No & Yes & No & \\
\hline c.900C > T (rs3212367) & p.F300F & 1 & 4 & No & Yes & No & {$[38]$} \\
\hline c. $927 \mathrm{C}<\mathrm{G}$ & p.L309L & 1 & & No & Yes & Yes & \\
\hline c.942A > G $($ rs 2228478$)$ & p.T314T & 249 & 170 & No & No & No & {$[25]$} \\
\hline c. $948 \mathrm{C}>\mathrm{T}(\mathrm{rs} 151318945)$ & p.S316S & 5 & 5 & No & Yes & No & $\mathrm{dbSNP}$ \\
\hline
\end{tabular}

${ }^{a}$ Damaging variants were those predicted as deleterious or intolerated by SIFT, SNPs3D, and PolyPhen in silico prediction tools.

${ }^{\mathrm{b}}$ Rare variants were defined as allele frequency less than $1 \%$.

${ }^{c}$ Variants were absent in dbSNP by using NM_002386.3 as contig transcript and works of Gerstenblith et al. [22] and García-Borrón et al. [23]. RHC, red hair colour variant.

Frequent non-RHC variants are shown in bold. 
TABLE 2: Association of different variant subgroups with melanoma risk.

\begin{tabular}{|c|c|c|c|c|c|}
\hline & Patients $^{c}(\mathrm{chr}=2262)$ & Controls $^{\mathrm{c}}(\mathrm{chr}=1738)$ & OR [95\% CI] & $P$ value & PAF (\%) \\
\hline Reference sequence $^{\mathrm{a}}$ & 936 & 976 & Ref. & Ref. & \\
\hline All $R$ variants ${ }^{b}$ & $500 / 0.22$ & 196/0.11 & $2.66[2.20-3.23]$ & $2.69 E-25$ & 15.8 \\
\hline \multicolumn{6}{|c|}{ Individual RHC variant } \\
\hline $\mathrm{D} 84 \mathrm{E}$ & $23 / 0.01$ & $13 / 0.007$ & 1.85 [0.89-3.87] & 0.092 & 0.8 \\
\hline $\mathrm{R} 142 \mathrm{H}$ & $29 / 0.01$ & $13 / 0.007$ & $2.33[1.16-4.75]$ & 0.012 & 1 \\
\hline $\mathrm{R} 151 \mathrm{C}$ & $211 / 0.09$ & $76 / 0.04$ & $2.90[2.18-3.86]$ & $7.95 \mathrm{E}-15$ & 7.4 \\
\hline R160W & $152 / 0.07$ & $59 / 0.03$ & $2.69[1.94-3.72]$ & $1.60 \mathrm{E}-10$ & 5.7 \\
\hline D294H & $85 / 0.04$ & $35 / 0.02$ & $2.53[1.66-3.87]$ & $3.10 \mathrm{E}-06$ & 2.9 \\
\hline All $r$ variants & $980 / 0.43$ & $678 / 0.39$ & $1.51[1.32-1.73]$ & $1.40 \mathrm{E}-09$ & 16.6 \\
\hline \multicolumn{6}{|l|}{ Frequent $r$ variants } \\
\hline V60L & $359 / 0.16$ & $254 / 0.15$ & $1.47[1.22-1.78]$ & $3.50 \mathrm{E}-05$ & 6.5 \\
\hline V92M & $188 / 0.08$ & $113 / 0.07$ & $1.73[1.34-2.25]$ & $1.30 \mathrm{E}-05$ & 4.5 \\
\hline $\mathrm{I} 155 \mathrm{~T}$ & $35 / 0.02$ & $14 / 0.008$ & $2.61[1.35-5.12]$ & 0.002 & 1.3 \\
\hline R163Q & $75 / 0.03$ & $57 / 0.03$ & 1.37 [0.95-1.98] & 0.087 & 1.2 \\
\hline Rare $r$ variants & $57 / 0.025$ & $31 / 0.017$ & $1.92[1.20-3.07]$ & 0.004 & 1.6 \\
\hline$D$ variants & $48 / 0.02$ & $21 / 0.01$ & $2.38[1.38-4.15]$ & 0.001 & 1.6 \\
\hline$n D$ variants & $9 / 0.004$ & $10 / 0.006$ & $0.94[0.35-2.51]$ & 1 & \\
\hline
\end{tabular}

${ }^{a}$ Number of alleles containing wild-type sequence or synonymous variants and used as reference.

${ }^{\mathrm{b}}$ All $R$ variants including D84E, R142H, R151C, R160W, and D294H.

${ }^{\mathrm{c}}$ Number of alleles/MAF (minor allelic frequency).

$R$ : red hair colour variant; $r$ : nonred hair colour variant; $D$ : predicted to be damaging; $n D$ : predicted to be nondamaging; OR: odds ratio; CI: confidence interval; PAF: population attributable fraction.

Statistically significant results are shown in bold. Ref, used as reference.

To assess the association of $R$ and $r$ variants with melanoma, we used Fisher's exact test, the number of haplotypes without any variants alleles (wild-type and synonymous variants) being considered as reference. Rare $r$ variants were thereafter classified into two subgroups according to functional prediction (predicted to be damaging $(D)$ or nondamaging $(n D)$ ), and their effects on melanoma risk were also tested.

A multivariate analysis adjusted for hair and eye colours, skin type, and nevus count was carried out to investigate the independent effect of $R$ and $r$ alleles on melanoma risk. $P$ values and their corresponding OR were calculated with logistic regression. Due to the interdependency of all our tests and the magnitude of our results, no correction for multiple testing was performed.

In order to quantify the impact of $M C 1 R R, r$, and $D$ variants on melanoma risk, their population attributable fractions $(\mathrm{PAF})$ were calculated as follows: $\mathrm{PAF}=(p \times(\mathrm{OR}-$ $1) /(p \times(\mathrm{OR}-1)+1)$, where $p$ is the proportion of controls carrying the risk alleles [34].

Finally, in order to investigate the respective role of $\mathrm{MClR}$ protein domains in melanoma, the number of $D$ and $n D$ variants in different domains was compared between patients and controls. Each protein domain was determined by ExPASy Bioinformatics Resource Portal (http://expasy.org/) using UniProtKB Q01726.2 as query.

\section{Results}

3.1. Characterization of MC1R Variants. By sequencing the entire MC1R coding sequence, we found $79 M C 1 R$ variants:
2 nonsense, 3 frameshift, 53 missense, and 21 silent variants (Table 1), 9\% of which were localized in the extracellular portion of the receptor, $65 \%$ in the transmembrane domains, and $25 \%$ in the cytoplasmic domains (Figure 1).

Five $R$ alleles (D84E, R142H, R151C, R160W, and D294H) and 5 frequent $r$ alleles (V60L, V92M, I155T, R163Q, and $\mathrm{T} 314 \mathrm{~T})$ were found in our cohorts. In addition, we found 69 rare $r$ alleles, consisting of 44 missense, 2 nonsense, 3 frameshift, and 20 silent variants. Interestingly, 25 were novel $M C 1 R$ variants, 15 of which (52\%) were predicted to have a functional impact ( $D$ variants). Amongst the 69 rare $r$ alleles, $40(58 \%)$ were predicted to be $D$ variants, including 35 missense, 2 nonsense, and 3 frameshift variants (Table 1).

3.2. Association of Different MC1R Variant Subgroups with Melanoma Risk. The association of different subgroups of $M C 1 R$ variants with melanoma risk was assessed as described in Section 2. Collectively, $R$ alleles were strongly associated with melanoma $(\mathrm{OR}=2.66$ [2.20-3.23]; $P=2.69 E-25)$ (Table 2). In addition, association of individual $R$ alleles with melanoma was significant (ORs $=$ from 2.33 to 2.9 ) for all $R$ variants except for D84E $(P=0.092)$. We calculated an estimated PAF due to $R$ variants of $15.8 \%$. By decreasing order, the PAFs were, respectively, 7.4 (R151C), 5.7 (R160W), 2.9 (D294H), 1 (R142H), and 0.8 (D84E) (Table 2).

Interestingly, $r$ alleles were also associated, although less strongly, with melanoma $(\mathrm{OR}=1.51[1.32-1.73] ; P=$ $1.40 E-09)$ (Table 2). In addition, three frequent $r$ alleles (V60L, V92M, and I155T) were associated individually with melanoma, but the association for the R163Q variant did not reach significance $(P=0.087)$. Of note, the I155T variant 


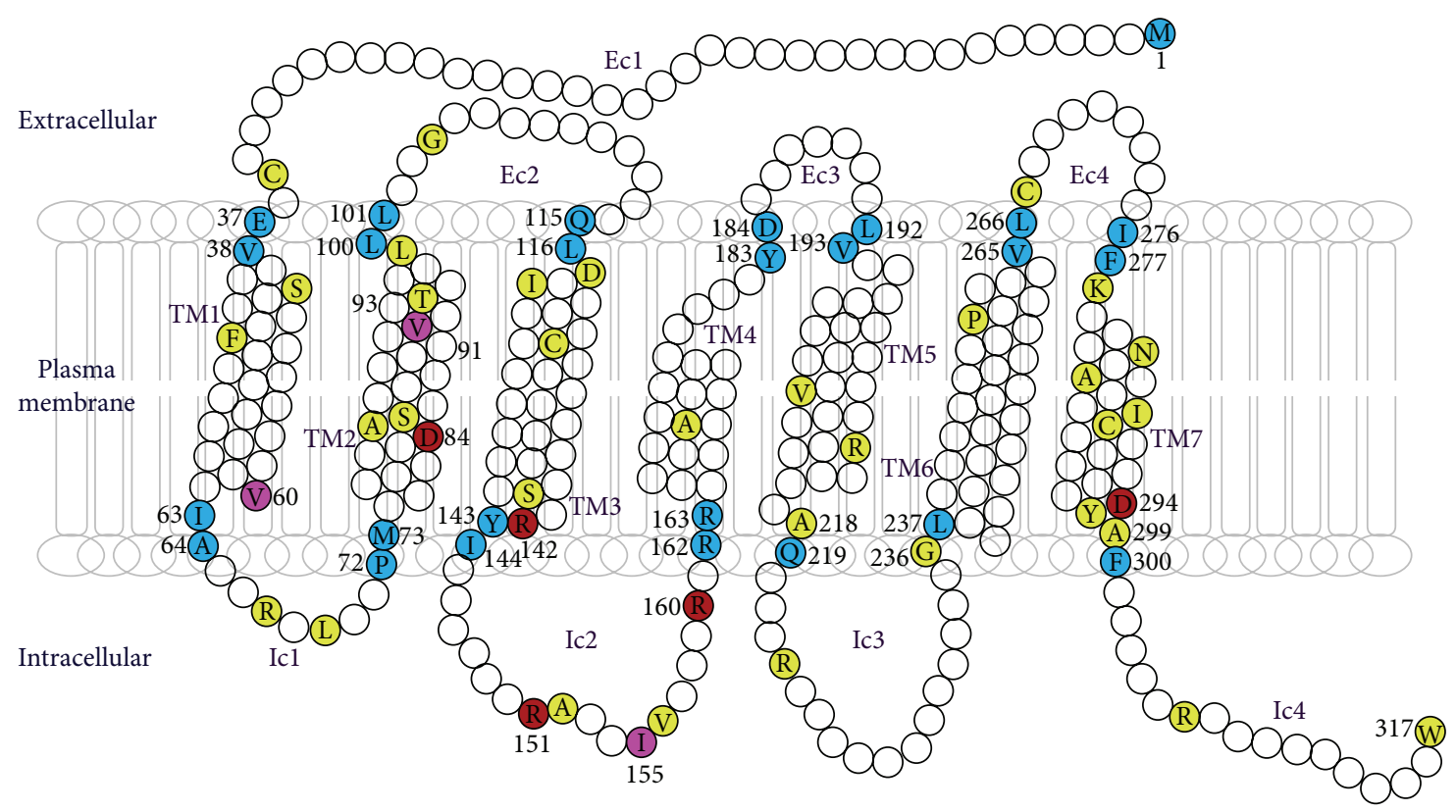

\footnotetext{
Residues located at protein domain boundaries

MC1R RHC $(R)$ variants

$M C 1 R$ frequent non-RHC $(r)$ variants

$M C 1 R$ predicted damaging $(D)$ variants
}

FIGURE 1: Structure of human melanocortin-1 receptor. Putative structure is drawn according to the two-dimensional model of Ringholm et al., 2004 [54]. The amino acid sequence corresponds to the wildtype consensus (UniProtKB Q01726.2). Each protein domain is framed by residues marked in blue. Residues with $R$, frequent $r$, and predicted-to-be-damaging $(D)$ alleles are shown in red, pink, and yellow, respectively. Ec: extracellular domain; Ic: intracellular domain; TM: transmembrane domain; $R$ : RHC alleles; $r$ : frequent non-RHC alleles; $D$ : predicted damaging variants.

associated almost as strongly as $R$ alleles with melanoma (OR $=2.61[1.35-5.12])$ and the other frequent $r$ alleles conferred risks equal to roughly half the risk of $R$ alleles (ORs $=$ from 1.47 to 1.73 ). The PAF of $r$ variants was very similar to that of $R$ variants (16.6\%). By decreasing order, the PAFs were, respectively, 6.5 (V60L), 4.5 (V92M), 1.3 (I155T), and 1.2 (R163Q) (Table 2).

Furthermore, rare $r$ variants were also strongly associated with melanoma $(\mathrm{OR}=1.92$ [1.20-3.07]; $P=0.004)$ (Table 2). We divided rare $r$ alleles into $D$ and $n D$ subgroups according to in silico functional predictions. Interestingly, $D$ variants were associated with melanoma susceptibility as strongly as $R$ alleles $(\mathrm{OR}=2.38[1.38-4.15] ; P=0.001)$. Of note, the estimated PAF of $D$ variants was $1.6 \%$ and contributed almost completely to the PAF of rare $r$ variants (Table 2). On the contrary, $n D$ variants had no impact on melanoma susceptibility $(P=1)$. Moreover, the average age at melanoma diagnosis of patients carrying $D$ variants was younger than that of patients without $D$ variants (45 and 54, resp.; $P=$ $0.04)$. Finally, $D$ variants, like $R$ variants, were also associated with familial melanoma $(\mathrm{OR}=4.78)$.

To investigate whether the effect of the two main $M C 1 R$ variant categories on melanoma susceptibility was independent of pigmentation traits, we conducted a multivariate analysis including the main clinical melanoma risk factors
TABLE 3: Multivariate analysis.

(a) $R$ variants

\begin{tabular}{lcc}
\hline & OR $[95 \% \mathrm{CI}]$ & $P$ value $^{\mathrm{a}}$ \\
\hline Hair colour & $0.88[0.69-1.12]$ & 0.292 \\
Eye colour & $\mathbf{2 . 3 0}[\mathbf{1 . 6 3}-\mathbf{3 . 2 6}]$ & $\mathbf{2 . 6 4 E}-\mathbf{0 6}$ \\
Skin type & $\mathbf{1 . 6 4}[\mathbf{1 . 1 7 - 2 . 3}]$ & $\mathbf{0 . 0 0 4}$ \\
Nevus count & $1.39[0.97-1.98]$ & 0.07 \\
$R$ variants & $\mathbf{2 . 2 2}[\mathbf{1 . 6 6 - 2 . 9 7}]$ & $\mathbf{6 . 0 0 E}-\mathbf{0 8}$ \\
\hline
\end{tabular}

(b) $r$ variants

\begin{tabular}{lcc}
\hline & OR $[95 \% \mathrm{CI}]$ & $P$ value $^{\mathrm{a}}$ \\
\hline Hair colour & $0.98[0.74-1.29]$ & 0.88 \\
Eye colour & $\mathbf{1 . 9 3}[\mathbf{1 . 4 5}-\mathbf{2 . 5 7}]$ & $\mathbf{1 . 2 0 \mathrm { E } - \mathbf { 0 6 }}$ \\
Skin type & $\mathbf{1 . 9 6}[\mathbf{1 . 4 9 - 2 . 5 7}]$ & $\mathbf{7 . 3 3 \mathrm { E } - \mathbf { 0 6 }}$ \\
Nevus count & $\mathbf{1 . 6}[\mathbf{1 . 1 8}-\mathbf{2 . 1 5}]$ & $\mathbf{0 . 0 0 2}$ \\
$r$ variants & $\mathbf{1 . 2 6}[\mathbf{1 . 0 4 - 1 . 5 2}]$ & $\mathbf{0 . 0 1 8}$ \\
\hline
\end{tabular}

${ }^{a} P$ value was calculated by logistic regression.

$R$ : red hair colour variant; $r$ : nonred hair colour variant.

Statistically significant results are shown in bold.

using logistic regression (Tables 3(a) and 3(b)). This showed a persistent role of $R$ and $r$ alleles on melanoma risk (respective ORs = 2.22 [1.66-2.97] and 1.26 [1.04-1.52]). 
TABLE 4: Localisation of $M C 1 R$ variants according to their classification and to their demonstrated or predicted functional impact.

\begin{tabular}{|c|c|c|c|c|c|}
\hline & \multirow{3}{*}{ Protein region } & \multirow{3}{*}{ RHC variant $(R)$} & \multicolumn{3}{|c|}{ Non-RHC variant $(r)$} \\
\hline & & & \multirow{2}{*}{ Frequent non-RHC $(r)$} & \multicolumn{2}{|c|}{ Rare $r$} \\
\hline & & & & $\begin{array}{l}\text { Predicted to be } \\
\text { damaging }(D)^{\mathrm{a}}\end{array}$ & $\begin{array}{c}\text { Predicted to be } \\
\text { nondamaging }(n D)^{\mathrm{a}}\end{array}$ \\
\hline $\mathrm{N}$-terminus & M1-E37 & & & 1 & 1 \\
\hline Transmembrane 1 & V38-I63 & & $\mathrm{x}$ & 4 & 5 \\
\hline Intracellular 1 & A64-P72 & & & 3 & 2 \\
\hline Transmembrane 2 & M73-L100 & $\mathrm{x}$ & $\mathrm{x}$ & 16 & 2 \\
\hline Extracellular 1 & L101-Q115 & & & 0 & 1 \\
\hline Transmembrane 3 & L116-Y143 & $\mathrm{x}$ & & 7 & 6 \\
\hline Intracellular 2 & I144-R162 & $\mathrm{x}$ & $\mathrm{x}$ & 4 & 0 \\
\hline Transmembrane 4 & R163-Y183 & & $\mathrm{x}$ & 1 & 0 \\
\hline Extracellular 2 & D184-L192 & & & 0 & 0 \\
\hline Transmembrane 5 & V193-A218 & & & 9 & 0 \\
\hline Intracellular 3 & Q219-G236 & & & 2 & 1 \\
\hline Transmembrane 6 & L237-V265 & & & 2 & 0 \\
\hline Extracellular 3 & L266-I276 & & & 1 & 1 \\
\hline Transmembrane 7 & F277-A299 & $\mathrm{x}$ & & 11 & 2 \\
\hline C-terminus & F300-W317 & & & 2 & 1 \\
\hline
\end{tabular}

${ }^{\mathrm{a}}$ Number of alleles found in each protein domain.

The crosses indicate localisation of RHC variants or frequent non-RHC variants.

3.3. Impact of the Different MC1R Protein Domains. In order to study the impact of MC1R protein domains on melanoma predisposition, the different classes of $M C 1 R$ variants $(R, r$, $D$, and $n D$ ) were positioned on the different protein domains (Figure 1).

Most MC1R variants were localized in six receptor domains: transmembrane 1, 2, 3, and 7, intracellular 2, and C terminal domains. Very few variants were located in the extracellular portion. Among these domains, variants located in the intracellular domain 2 and in the transmembrane domain 7 had the highest impact on melanoma risk $(\mathrm{OR}=$ $2.75[2.22-3.40]$ and $\mathrm{OR}=2.48$ [1.67-3.69]).

The repartition of $R, r, D$, and $n D$ variants in each protein domain indicated in Table 4 showed that $63 \%$ of $D$ variants were located in four domains (intracellular 2 and transmembrane 2,5 , and 7) whereas only $18 \%$ of $n D$ variants were located in these domains $(P<0.0001)$. Importantly, three of these four domains also contain at least one $R$ variant, suggesting an important role of these domains in MC1R function and pathogenicity.

\section{Discussion}

$M C 1 R$ variants are usually classified into two main categories, $\mathrm{RHC}(R)$ and non-RHC $(r)$, according to their association or not with the red hair colour phenotype [21, 24, 27, 55]. For the past ten years several association studies have demonstrated the importance of $R$ alleles on melanoma predisposition [28, $29,42,56,57]$. However, the influence of rare $M C 1 R$ variants on melanoma predisposition has been poorly investigated which prompted us to study in detail the role of these variants in the French population.

In this study, we confirmed the association of most $R$ alleles and melanoma risk with strengths that were close to those observed in previous studies [28, 29, 42, 56, 57].

We also showed a clear association of frequent MC1R $r$ alleles, especially V60L, V92M, and I155T, with melanoma. In an early meta-analysis neither of them was found to be associated with melanoma [55], whereas, in a more recent and larger meta-analysis, both were associated with melanoma [57]. V60L is a loss of function variant with reduced coupling to the cAMP signalling $[50,53]$ and V92M has a lower affinity for $\alpha$-MSH than wild-type MC1R and a decreased ability to stimulate the production of cAMP [23]. These functional data argue for an association of theses variants with melanoma risk.

Even though the OR of $R$ alleles was much higher than that of $r$ alleles, their PAFs were very close $(15.8 \%$ for $R$ and $16.6 \%$ for $r$ ) suggesting that the impact of $r$ alleles on melanoma seems to be important in the French population. Notably, in our work, the individual PAFs of V60L and V92M (6.5\% and $4.5 \%)$ were very close to that of $R$ alleles $\mathrm{R} 151 \mathrm{C}$ and R160W (7.4\% and 5.7\%). Our results are different from that published by Williams et al., in which the PAF of $r$ variants is only 7.4. This may be due at least, in part, to the high allelic frequency of $r$ variants observed in French melanoma patients (0.43) (versus 0.33 in Williams meta-analysis) [57]. This further emphasises the role $r$ alleles in melanoma risk according to the ethnical background of the population studied. In addition, both $R$ and $r$ alleles remained associated with melanoma risk in multivariate analyses, suggesting that 
they exert a role in melanoma risk independently of their effect on pigmentation, as previously suggested.

In this work we identified 25 variants that have not been reported before [22, 23, 31, 47], further underscoring the highly polymorphic character of $M C 1 R$. According to Gerstenblith's work, the proportion of rare $M C 1 R$ variants varies across populations and within Caucasian populations [23]. In our study, the proportion of rare variants (87\%) was close to that described in Scherer's work ( $74 \%$ in Germany and $78 \%$ in Spain) [31]. Interestingly, rare variants predicted to be damaging ( $D$ variants) were associated with melanoma as strongly as $R$ alleles $(\mathrm{OR}=2.38[1.38-4.15])$ whereas variants not predicted to be damaging $(n D)$ had no effect on melanoma. In addition, PAF of $D$ variants (1.6\%) was higher than two $R$ variants (R142H and D84E), which seems to indicate that the contribution of this subgroup in melanoma predisposition should be taken into consideration, at least in the French population.

Yet, there is a limitation in our work: the absence of functional studies concerning the potential effects of these novel $M C 1 R$ variants, notably on $\alpha$-MSH binding, receptor cellular localisation, and cAMP signalling.

Finally, the majority of $D$ variants were located in the same domains as the $R$ alleles (intracellular 2 and transmembrane 2, 5, and 7, Table 4 and Figure 1). It had been shown before that there was a similar localization of $D$ variants in the German, Spanish, and Italian populations [29, 31] suggesting an important role of these domains in the receptor's function.

\section{Conclusion}

In this large study we confirmed the role of $M C 1 R R$ alleles in melanoma susceptibility and clearly showed that $M C 1 R$ $r$ alleles also significantly increase the risk of melanoma. In addition, we defined the role of rare $M C 1 R$ variants and proposed a novel class of $D$ variants that are strong melanoma risk factors. These findings might help in the definition of high-risk melanoma subgroups that could be targeted for melanoma prevention.

\section{Conflict of Interests}

The authors declare that there is no conflict of interests regarding the publication of this paper.

\section{Acknowledgments}

The authors would like to thank the Société Française de Dermatologie for supporting their research. They also thank the dermatological departments of Ambroise Paré, Bichat, Cochin, Henri Mondor, and Saint Louis hospitals for participating in the MelanCohort project and the Etablissement Français du Sang for providing control blood samples. They thank the Centre de Recherche Biologique of Bichat Hospital for sample preparation. Importantly, they would like to thank the patients and control subjects who participated in this study.

\section{References}

[1] M. A. Tucker and A. M. Goldstein, "Melanoma etiology: where are we?" Oncogene, vol. 22, no. 20, pp. 3042-3052, 2003.

[2] F. Demenais, H. Mohamdi, V. Chaudru et al., "Association of $M C 1 R$ variants and host phenotypes with melanoma risk in CDKN2A mutation carriers: a GenoMEL study," Journal of the National Cancer Institute, vol. 102, no. 20, pp. 1568-1583, 2010.

[3] A. A. Nelson and H. Tsao, "Melanoma and genetics," Clinics in Dermatology, vol. 27, no. 1, pp. 46-52, 2009.

[4] M. C. Fargnoli, G. Argenziano, I. Zalaudek, and K. Peris, "Highand low-penetrance cutaneous melanoma susceptibility genes," Expert Review of Anticancer Therapy, vol. 6, no. 5, pp. 657-670, 2006.

[5] M. H. Abdel-Rahman, R. Pilarski, C. M. Cebulla et al., "Germline BAP1 mutation predisposes to uveal melanoma, lung adenocarcinoma, meningioma, and other cancers," Journal of Medical Genetics, vol. 48, no. 12, pp. 856-859, 2011.

[6] J. R. Testa, M. Cheung, J. Pei et al., "Germline BAP1 mutations predispose to malignant mesothelioma," Nature Genetics, vol. 43, no. 10, pp. 1022-1026, 2011.

[7] T. Wiesner, A. C. Obenauf, R. Murali et al., "Germline mutations in BAP1 predispose to melanocytic tumors," Nature Genetics, vol. 43, no. 10, pp. 1018-1022, 2011.

[8] D. L. Duffy, Z. Z. Zhao, R. A. Sturm, N. K. Hayward, N. G. Martin, and G. W. Montgomery, "Multiple pigmentation gene polymorphisms account for a substantial proportion of risk of cutaneous malignant melanoma," Journal of Investigative Dermatology, vol. 130, no. 2, pp. 520-528, 2010.

[9] M. R. Gerstenblith, J. Shi, and M. T. Landi, "Genome-wide association studies of pigmentation and skin cancer: a review and meta-analysis," Pigment Cell and Melanoma Research, vol. 23, no. 5, pp. 587-606, 2010.

[10] D. F. Gudbjartsson, P. Sulem, S. N. Stacey et al., "ASIP and TYR pigmentation variants associate with cutaneous melanoma and basal cell carcinoma," Nature Genetics, vol. 40, no. 8, pp. 886891, 2008.

[11] H. Nan, P. Kraft, D. J. Hunter, and J. Han, "Genetic variants in pigmentation genes, pigmentary phenotypes, and risk of skin cancer in Caucasians," International Journal of Cancer, vol. 125, no. 4, pp. 909-917, 2009.

[12] N. Soufir, R. Meziani, J.-J. Lacapère et al., "Association between endothelin receptor B nonsynonymous variants and melanoma risk," Journal of the National Cancer Institute, vol. 97, no. 17, pp. 1297-1301, 2005.

[13] J. H. Barrett, M. M. Iles, M. Harland et al., "Genome-wide association study identifies three new melanoma susceptibility loci," Nature Genetics, vol. 43, pp. 1108-1113, 2011.

[14] M. H. Law, G. W. Montgomery, K. M. Brown et al., "Metaanalysis combining new and existing data sets confirms that the TERT-CLPTM1L locus influences melanoma risk," Journal of Investigative Dermatology, vol. 132, no. 2, pp. 485-487, 2012.

[15] S. Macgregor, G. W. Montgomery, J. Z. Liu et al., "Genome-wide association study identifies a new melanoma susceptibility locus at 1q21.3," Nature Genetics, vol. 43, pp. 1114-1118, 2011.

[16] T. Rafnar, P. Sulem, S. N. Stacey et al., "Sequence variants at the TERT-CLPTM1L locus associate with many cancer types," Nature Genetics, vol. 41, no. 2, pp. 221-227, 2009.

[17] S. N. Stacey, P. Sulem, G. Masson et al., "New common variants affecting susceptibility to basal cell carcinoma," Nature Genetics, vol. 41, pp. 909-914, 2009. 
[18] G. S. Barsh, "The genetics of pigmentation: from fancy genes to complex traits," Trends in Genetics, vol. 12, no. 8, pp. 299-305, 1996.

[19] J. L. Rees, “The genetics of sun sensitivity in humans," American Journal of Human Genetics, vol. 75, no. 5, pp. 739-751, 2004.

[20] F. Rouzaud, A. L. Kadekaro, Z. A. Abdel-Malek, and V. J. Hearing, "MC1R and the response of melanocytes to ultraviolet radiation," Mutation Research, vol. 571, no. 1-2, pp. 133-152, 2005.

[21] J. V. Schaffer and J. L. Bolognia, "The melanocortin-1 receptor: red hair and beyond," Archives of Dermatology, vol. 137, no. 11, pp. 1477-1485, 2001.

[22] M. R. Gerstenblith, A. M. Goldstein, M. C. Fargnoli, K. Peris, and M. T. Landi, "Comprehensive evaluation of allele frequency differences of MC1R variants across populations," Human Mutation, vol. 28, no. 5, pp. 495-505, 2007.

[23] J. C. García-Borrón, B. L. Sánchez-Laorden, and C. JiménezCervantes, "Melanocortin-1 receptor structure and functional regulation," Pigment Cell Research, vol. 18, no. 6, pp. 393-410, 2005.

[24] M. Bastiaens, J. Ter Huurne, N. Gruis et al., "The melanocortin1-receptor gene is the major freckle gene," Human Molecular Genetics, vol. 10, no. 16, pp. 1701-1708, 2001.

[25] N. F. Box, J. R. Wyeth, L. E. O'Gorman, N. G. Martin, and R. A. Sturm, "Characterization of melanocyte stimulating hormone receptor variant alleles in twins with red hair," Human Molecular Genetics, vol. 6, no. 11, pp. 1891-1897, 1997.

[26] E. Healy, N. Flannagan, A. Ray et al., "Melanocortin-1-receptor gene and sun sensitivity in individuals without red hair," The Lancet, vol. 355, no. 9209, pp. 1072-1073, 2000.

[27] P. Valverde, E. Healy, I. Jackson, J. L. Rees, and A. J. Thody, "Variants of the melanocyte-stimulating hormone receptor gene are associated with red hair and fair skin in humans," Nature Genetics, vol. 11, no. 3, pp. 328-330, 1995.

[28] U. Brudnik, W. Branicki, A. Wojas-Pelc, and P. Kanas, "The contribution of melanocortin 1 receptor gene polymorphisms and the agouti signalling protein gene 8818A $>$ G polymorphism to cutaneous melanoma and basal cell carcinoma in a Polish population," Experimental Dermatology, vol. 18, no. 2, pp. 167174, 2009.

[29] M. T. Landi, P. A. Kanetsky, S. Tsang et al., "MC1R, ASIP, and DNA repair in sporadic and familial melanoma in a mediterranean population," Journal of the National Cancer Institute, vol. 97, no. 13, pp. 998-1007, 2005.

[30] P. A. Kanetsky, T. R. Rebbeck, A. J. Hummer et al., "Populationbased study of natural variation in the melanocortin-1 receptor gene and melanoma," Cancer Research, vol. 66, no. 18, pp. 93309337, 2006.

[31] D. Scherer, E. Nagore, J. L. Bermejo et al., "Melanocortin receptor 1 variants and melanoma risk: a study of 2 European populations," International Journal of Cancer, vol. 125, no. 8, pp. 1868-1875, 2009.

[32] J. di Lucca, M. Guedj, J. J. Lacapère et al., "Interactions between ultraviolet light exposure and DNA repair gene polymorphisms may increase melanoma risk," British Journal of Dermatology, vol. 162, pp. 891-893, 2010.

[33] H.-H. Hu, M. Guedj, V. Descamps et al., "Assessment of tyrosinase variants and skin cancer risk in a large cohort of French subjects," Journal of Dermatological Science, vol. 64, no. 2, pp. 127-133, 2011.
[34] M. Ibarrola-Villava, H.-H. Hu, M. Guedj et al., " $M C 1 R$, SLC45A2 and TYR genetic variants involved in melanoma susceptibility in Southern European populations: results from a Metaanalysis," European Journal of Cancer, vol. 48, pp. 2183-2191, 2012.

[35] M. C. Fargnoli, S. Chimenti, G. Keller, H. Höfler, and K. Peris, "Identification of four novel melanocortin 1 receptor (MC1R) gene variants in a Mediterranean population," Human Mutation, vol. 21, no. 6, p. 655, 2003.

[36] L. Pastorino, R. Cusano, W. Bruno et al., "Novel MC1R variants in Ligurian melanoma patients and controls," Human Mutation, vol. 24, no. 1, p. 103, 2004.

[37] W. Branicki, U. Brudnik, T. Kupiec, P. Wolañska-Nowak, and A. Wojas-Pelc, "Determination of phenotype associated SNPs in the MC1R gene," Journal of Forensic Sciences, vol. 52, no. 2, pp. 349-354, 2007.

[38] B. K. Rana, D. Hewett-Emmett, L. Jin et al., "High polymorphism at the human melanocortin 1 receptor locus," Genetics, vol. 151, no. 4, pp. 1547-1557, 1999.

[39] P. R. John, K. Makova, W.-H. Li, T. Jenkins, and M. Ramsay, "DNA polymorphism and selection at the melanocortin-1 receptor gene in normally pigmented Southern African individuals," Annals of the New York Academy of Sciences, vol. 994, pp. 299-306, 2003.

[40] C. Jiménez-Cervantes, S. Germer, P. González, J. Sánchez, C. O. Sánchez, and J. C. García-Borrón, "Thr40 and Met122 are new partial loss-of-function natural mutations of the human melanocortin 1 receptor," FEBS Letters, vol. 508, no. 1, pp. 44-48, 2001.

[41] D. I. Våge, D. Lu, H. Klungland, S. Lien, S. Adalsteinsson, and R. D. Cone, "A non-epistatic interaction of agouti and extension in the fox, Vulpes vulpes," Nature Genetics, vol. 15, no. 3, pp. 311315, 1997.

[42] E. Matichard, P. Verpillat, R. Meziani et al., "Melanocortin 1 receptor $(M C 1 R)$ gene variants may increase the risk of melanoma in France independently of clinical risk factors and UV exposure," Journal of medical genetics, vol. 41, no. 2, article e13, 2004.

[43] P. R. John and M. Ramsay, "Four novel variants in MC1R in redhaired South African individuals of European descent: S83P, Y152X, A171D, P256S," Human Mutation, vol. 19, no. 4, pp. 461462, 2002.

[44] D. Scherer, J. L. Bermejo, P. Rudnai et al., "MC1R variants associated susceptibility to basal cell carcinoma of skin: Interaction with host factors and XRCC3 polymorphism," International Journal of Cancer, vol. 122, no. 8, pp. 1787-1793, 2008.

[45] M. Liboutet, M. Portela, G. Delestaing et al., "MC1R and PTCH gene polymorphism in French patients with basal cell carcinomas," Journal of Investigative Dermatology, vol. 126, no. 7, pp. 1510-1517, 2006.

[46] R. M. Harding, E. Healy, A. J. Ray et al., "Evidence for variable selective pressures at MC1R," American Journal of Human Genetics, vol. 66, no. 4, pp. 1351-1361, 2000.

[47] A. B. Pérez-Oliva, L. P. Fernéndez, C. Detorre et al., "Identification and functional analysis of novel variants of the human melanocortin 1 receptor found in melanoma patients," Human Mutation, vol. 30, pp. 811-822, 2009.

[48] K. Nakayama, A. Soemantri, F. Jin et al., "Identification of novel functional variants of the melanocortin 1 receptor gene originated from Asians," Human Genetics, vol. 119, no. 3, pp. 322-330, 2006. 
[49] V. Chaudru, K. Laud, M.-F. Avril et al., "Melanocortin-1 receptor (MC1R) gene variants and dysplastic nevi modify penetrance of CDKN2A mutations in French melanoma-prone pedigrees," Cancer Epidemiology Biomarkers and Prevention, vol. 14, no. 10, pp. 2384-2390, 2005.

[50] B. L. Sánchez-Laorden, C. Herraiz, J. C. Valencia, V. J. Hearing, C. Jiménez-Cervantes, and J. C. García-Borrón, "Aberrant trafficking of human melanocortin 1 receptor variants associated with red hair and skin cancer: steady-state retention of mutant forms in the proximal Golgi," Journal of Cellular Physiology, vol. 220, no. 3, pp. 640-654, 2009.

[51] C. Herraiz, C. Jiménez-Cervantes, P. Zanna, and J. C. GarcíaBorrón, "Melanocortin 1 receptor mutations impact differentially on signalling to the cAMP and the ERK mitogen-activated protein kinase pathways," FEBS Letters, vol. 583, no. 19, pp. 3269-3274, 2009.

[52] J. Sánchez-Más, C. Olivares-Sánchez, G. Ghanem et al., "Lossof-function variants of the human melanocortin-1 receptor gene in melanoma cells define structural determinants of receptor function," European Journal of Biochemistry, vol. 269, pp. 61336141, 2002.

[53] H. B. Schiöth, S. R. Phillips, R. Rudzish, M. A. Birch-Machin, J. E. S. Wikberg, and J. L. Rees, "Loss of function mutations of the human melanocortin 1 receptor are common and are associated with red hair," Biochemical and Biophysical Research Communications, vol. 260, no. 2, pp. 488-491, 1999.

[54] A. Ringholm, J. Klovins, R. Rudzish, S. Phillips, J. L. Rees, and H. B. Schiöth, "Pharmacological characterization of loss of function mutations of the human melanocortin 1 receptor that are associated with red hair," Journal of Investigative Dermatology, vol. 123, no. 5, pp. 917-923, 2004.

[55] S. Raimondi, F. Sera, S. Gandini et al., "MC1R variants, melanoma and red hair color phenotype: a meta-analysis," International Journal of Cancer, vol. 122, no. 12, pp. 2753-2760, 2008.

[56] C. Kennedy, J. Ter Huurne, M. Berkhout et al., "Melanocortin 1 receptor $(M C 1 R)$ gene variants are associated with an increased risk for cutaneous melanoma which is largely independent of skin type and hair color," Journal of Investigative Dermatology, vol. 117, no. 2, pp. 294-300, 2001.

[57] P. F. Williams, C. M. Olsen, N. K. Hayward, and D. C. Whiteman, "Melanocortin 1 receptor and risk of cutaneous melanoma: a meta-analysis and estimates of population burden," International Journal of Cancer, vol. 129, no. 7, pp. 17301740, 2011. 

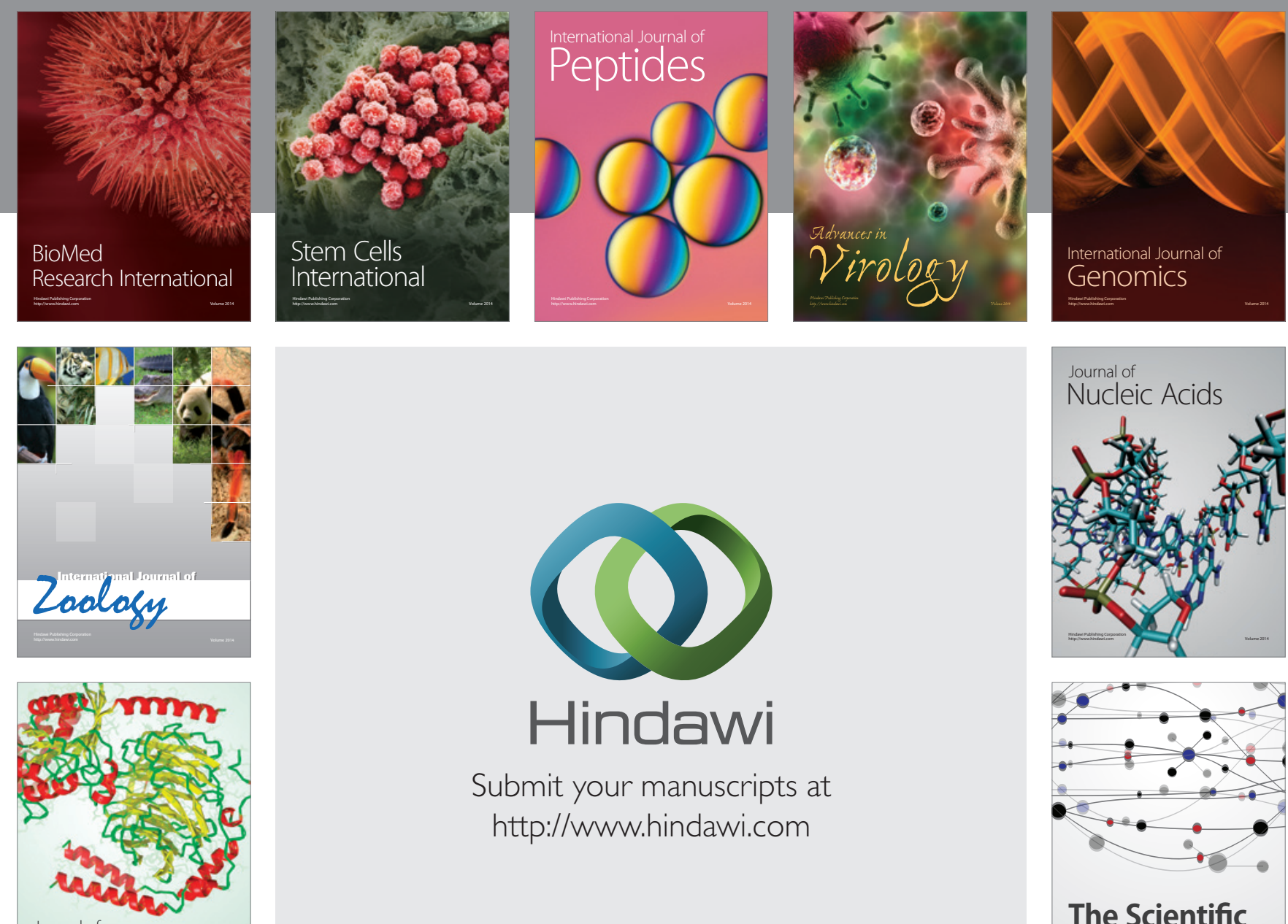

Submit your manuscripts at

http://www.hindawi.com

Journal of
Signal Transduction
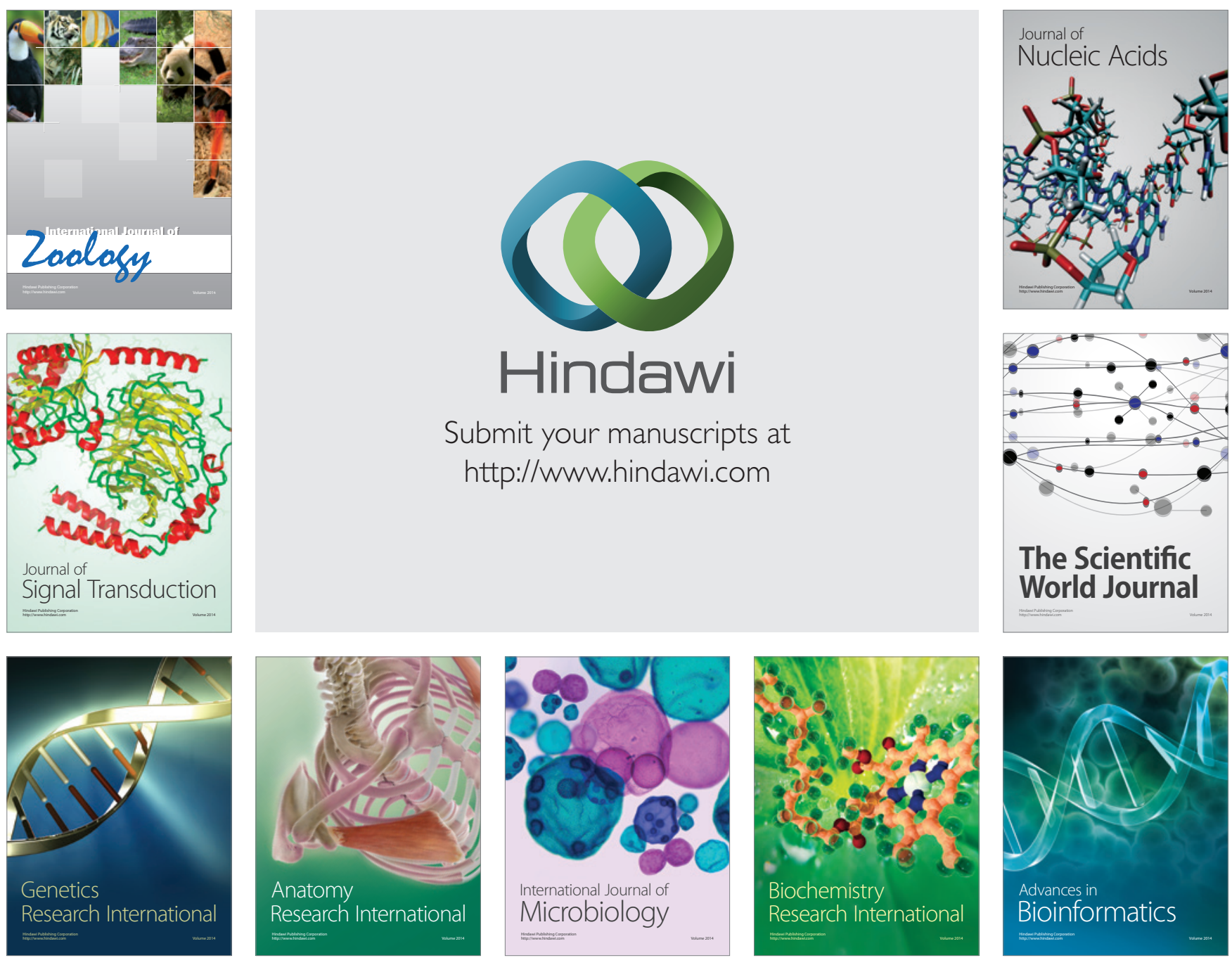

The Scientific World Journal
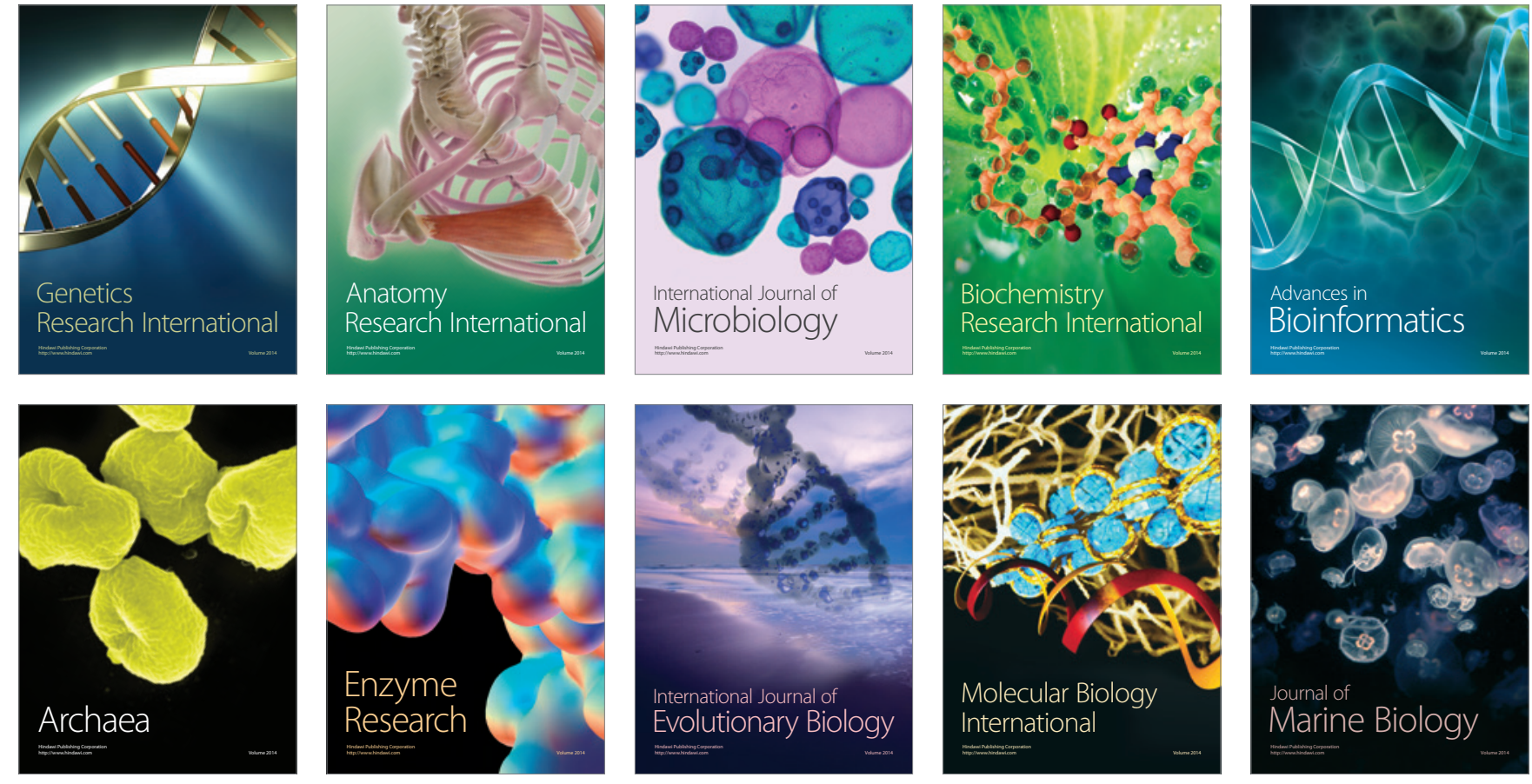